\title{
Data is or data are
}

\author{
Stephen Hancocks OBE \\ Editor-in-Chief
}

The BDJ Upfront section includes editorials, letters, news, book reviews and interviews. Please direct your correspondence to the News Editor,

Kate Quinlan at BDJNews@nature.com. Press releases or articles may be edited, and should include a colour photograph if possible.

$\mathrm{O}$ ne of the most frequent corrections we have to make to content submitted to the journal is to change 'data is' to 'data are. While there is still controversy about which is correct since both are commonly used as interchangeable, by definition datum is the singular and data represents the plural.

We have been reading a lot about data recently since it has emerged that our personal data have been traded through such otherwise seemingly innocent online routes as Facebook. There is no doubt that information is power, which we know corrupts, and in turn also promises financial return. As with all such human interactions though it is the context in which the information is used which dictates the tipping point between it being advantageous, benign or threatening.

Much the same may be applied to the whole area of research and the uses to which it is put. We all research all the time, seeking evidence-based answers. Primarily this is because we want to invest our resources in the most efficient way. Having information and knowledge enable us make the best choices in our social, professional and business lives. Advertisers know this very well: : $\ldots$...eight out of ten cats prefer...', '... acts faster than any other headache remedy', '...is more fuel efficient than all other cars in its class', and so forth. We rarely take the initiative to question such claims further, assuming that as trusted brands they will tell us the truth. Additionally, we have reassurance that authorities - the 'they' to which we often refer - would not allow mistruths to be perpetuated.

In the case of adverts this might be the Advertising Standards Authority, whose criteria 'legal, decent, honest, truthful' have stood the test of time with an ethical succinctness. In terms of dental research peer review is recognised as providing a similar guarantee of robustness and truth. This Journal, amongst many, is a prime example of this having generated, nurtured and closely monitored it for over 130 years.

What we need to be conscious of in the modern world of sound bites, tweets and other forms of communication that are crushed by brevity, is that we do not succumb to decisiveness by necessity of speed. There are times, particularly where biology is concerned, when only a long explanation is good enough. Caries is a prime example. Since the majority of us spend our lifetimes dealing with its aetiology, prevention, treatment and consequences we know only too well that attempting to distil a message to a patient is virtually impossible. one might legitimately quote the century-old work of G. V. Black and his cavity preparations. However, this would hopefully be in the context of explaining why such thinking was no long current or appropriate and would continue by describing perhaps minimal intervention dentistry and how changes in knowledge, diagnosis, materials and technology had shaped our thinking and actions. Similarly, one might describe the work of H. Trendley Dean whose observation of the different caries levels in various locations and the mapping thereof led to the discovery of the health benefits of optimally fluoridated water supplies. A fascinat-

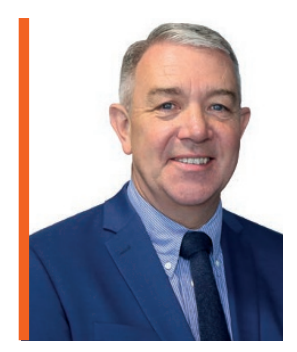

\section{'There are times, particularly where biology is concerned, when only a long explanation is good enough...'}

'Don't eat sweets' is of course meaningless, as are multitudes of other abbreviated attempts at motivation. What is required is knowledge of the subject, the patient and the context.

This is where jumping on the briefest of summaries of research can prove to be not only erroneous but also counterproductive and where access to the provision of the full context is required. In a fast moving world there is also an unfortunate tendency for those on a mission, or with a particular passion or belief, to selectively quote research or data to support their cause. One might, for example, be suspicious of this when research is quoted from long ago. Why is it not more contemporary? It may be that there has been no recent study of the subject area, or that the work cited is still the most robust. There are also situations in which 'historical' research is relevant to help set the scene.

In terms of treating caries, as an instance, ing epidemiological detective story. But this would be given as background information and not presented as new evidence.

One might on the other hand be suspicious of a campaign that quoted a single study from, say the 1960s, which apparently showed that fluoride led directly to some form of cancer, when the over-riding body of evidence before and certainly since then indicates that no such association exists.

These uses, or misuses, of research and of data are likely to become more important to us in the future. Arguably those who we can trust are dwindling in number and routes by which we gather information, or more pertinently are fed information, become faster, less precise and yet of apparently greater importance for our instant reaction and decision. Whether 'data is' or 'data are', the manipulation and trading of facts are real and present dangers.

DOI: 10.1038/sj.bdj.2018.272 